\title{
Seroprevalence of $Q$ fever in sheep and goats from the Marmara region, Turkey
}

\author{
Mustafa Sencer Karagul ${ }^{1}$, Mehmet Engin Malal $^{2}$, Kadir Akar ${ }^{2}$ \\ ${ }^{1}$ Kartepe Vocational School of Equine Science, Kocaeli University, 41380 Kocaeli, Turkey ${ }^{1}$ \\ ${ }^{2}$ Aerobic Vaccines Production Laboratory, Pendik Veterinary Control Institute, 34890 Istanbul, Turkey ${ }^{2}$ \\ ${ }^{3}$ Brucella Reference Diagnostic and Vaccine Production Laboratory, Pendik Veterinary Control Institute, 34890 Istanbul, Turkey ${ }^{2}$ \\ sencer.karagul@kocaeli.edu.tr
}

Received: April 19, 2019 Accepted: November 5, 2019

\begin{abstract}
Introduction: The aim of this study was to investigate Q fever seroprevalence in sheep and goats in the Marmara region. $\mathrm{Q}$ fever is a zoonotic disease caused by Coxiella burnetii. In ruminants, the disease causes reproductive disorders, premature births and stillbirths. Material and Methods: Blood samples of sheep and goats were collected from the Marmara region of Turkey and a commercial ELISA was used for detection of specific antibodies to C. burnetii. A total of 832 samples (627 from sheep and 205 from goats) obtained from 126 herds located in 110 villages in 63 municipalities across all 11 provinces were utilised. Results: Total seroprevalence was found to be $13.22 \%$, while the proportion of seropositive herds was determined to be over threefold higher at $42.85 \%$. The seroprevalence for sheep was found to be $14.19 \%$, and for goats $10.24 \%$. The herd seropositivity rate for sheep of $46.31 \%$ and for goats of $32.25 \%$ were also over threefold higher than the species-level seroprevalences. The provincial seroprevalence varied between $1.38 \%$ and $21.79 \%$. Conclusion: This study confirms the presence of C. burnetii in sheep and goat herds in the Marmara region and provides original seroprevalence data in hitherto uninvestigated provinces. The data gathered are beneficial for evaluation and elaboration of the seroprevalence of Q fever in sheep and goats in the Marmara region. Surveillance studies should be maintained, particularly in provinces with high seropositivity rates.
\end{abstract}

Keywords: Coxiella burnetii, ELISA, Q fever, ruminant, seroprevalence.

\section{Introduction}

Q fever is a zoonotic disease of which the aetiological agent is Coxiella burnetii (10). It occurs in many countries of the world $(10,16,24)$ and in the EU, it is a list B zoonosis as established by Directive 2003/99/EC and the amendment of Directive 2009/99/EC. EU member states are required by the latter Directive on the monitoring of zoonotic agents to monitor and report on cases of coxiellosis in animals if warranted by the epidemiological situation. Fourteen EU member states and Switzerland have reported coxiellosis as a notifiable disease in animals (22). Q fever is an endemic disease with diverse geographic and climatic areas which exclude only Antarctica and New Zealand $(1,4,9,15,25)$. According to the data revealed in the World Animal Health Information System (WAHIS) interface from 2018, the disease is present in such countries as Afghanistan, the USA, Australia, Germany, France, and Uruguay (27). Several wild and domestic animals, birds, and ticks are considered to be the reservoirs of the organism $(8,10,16)$, and ticks could have a role in the transmission of the infection $(8,25)$. However, domestic ruminants such as cattle, sheep, and goats, which are the main reservoirs, are generally considered to be the possible sources of Q fever in humans $(8,10,13,16,25)$. Infected animals such as sheep, goats, and cows are capable of shedding the organism persistently without showing any noticeable manifestation, with even fever absent $(10,16,24)$. Females especially shed a great amount of bacteria through birth discharge, placenta, and foetal membranes at the time of abortion or regular parturition $(1,4,10)$. Shedding the agent via faeces, urine, vaginal secretion, and milk at high concentration lasts for several months $(1,6,10,13)$. Placental tissue containing more than $10^{9}$ bacteria per $\mathrm{g}$ is a possible way for the pathogen to pass into an animal's surroundings. Despite the fact that milk includes a large amount of $C$. burnetii, it is not the most common means of acquiring $\mathrm{Q}$ fever $(8,16)$.

The disease generally leads to abortions happening sporadically or it may emerge with outbreaks of abortions in small ruminants. Recovery without any complications often follows the abortions. Q fever 
infection might persist for years, and even for the whole life of the animal (24). The common paths of transmission of human infections are by inhalation of an infectious aerosol or dust $(6,13)$ and ingestion of fresh dairy products or raw milk $(4,9,14)$. Unlike other animal species, sheep and goats, which are ruminant reservoirs, are commonly included in the epidemiology of the disease in humans (4). There could be both sexual and vertical transmission in animals as well as airborne dissemination and ingestion (25).

C. burnetii is a gram-negative obligate intracellular pathogen $(1,10,24)$. The organism is highly stable in the environment owing to its spore-like form which is resistant to adverse factors $(9,17,25)$ such as high temperature, dehydration, and exposure to disinfectants and ultraviolet light (4). The extraordinary resistance of the agent to chemicals and physical conditions make it capable of surviving in the environment $(4,17)$. Because of its airborne dissemination possibility, resistance in the environment, and low infective dose with high morbidity, C. burnetii is classified as a group B potential bioterrorism agent $(2,19,25)$.

Complications of the human disease in the chronic form may lead to serious problems and even death (25). In ruminants, the clinical signs of $\mathrm{Q}$ fever include reproductive failures, infertility, metritis, and retained placenta, all of which can cause serious economic losses $(1,13,25)$. The diagnosis of $Q$ fever usually depends on serology $(8,23,24)$. Such testing is preferred because clinical diagnosis is difficult (8) and handling C. burnetii is risky $(8,15)$. Serological analyses are helpful in the surveillance of herds $(18,25)$. It should be borne in mind that animals with an acute infection history continue to have seropositivity for several years; on the other hand, a significant percentage of carriershedder animals may show negative results (25). Among different tests that could be carried out, microagglutination, the complement fixation test (CFT), and particularly the indirect immunofluorescence assay (IFA) and ELISA are the common methods used for the detection of specific C. burnetii antibodies $(8,15,25)$, IFA being proposed as a reference method (14). However, it is stated that IFA is not convenient for epidemiological research when many samples must be assayed (19). Therefore, when it comes to screening great numbers of animals, ELISA is recommended for regular serological testing $(11,14,25,26)$.

The prevalence of $\mathrm{Q}$ fever is higher than reported, mainly because of the lack of well-organised surveillance of the disease, especially in the countries where the disease is common $(16,25)$. The first proof of Q fever's prevalence in Turkey appeared with an outbreak in 1947 (15). To our knowledge, the seroprevalence of $\mathrm{Q}$ fever in sheep and goats in the Turkish Marmara region including all provinces has not been reported in the literature so far. Serosurveys have shown that Q fever is endemic in humans and animals in Turkey and it is obvious that this disease constitutes an important risk to both human and animal health. With this impetus in mind, the aim of the present study is to determine the seroprevalence of $\mathrm{Q}$ fever in sheep and goats in all 11 provinces in the Marmara region in Turkey.

\section{Material and Methods}

The study was carried out in the Pendik Veterinary Control Institute (PVCI), which includes the National Reference Laboratory for Q fever. The blood samples analysed were collected within the scope of serosurvey programmes to establish control strategies against the disease. A total of 832 samples were obtained from 126 herds (95 sheep herds and 31 goat herds) located in 110 villages in 63 municipalities across all 11 provinces of the Marmara region. From each province, the number of samples collected was between 69 and 85 . The location of the provinces is shown in Fig. 1.

Fig. 1. The provinces in the Marmara region from which the samples were collected

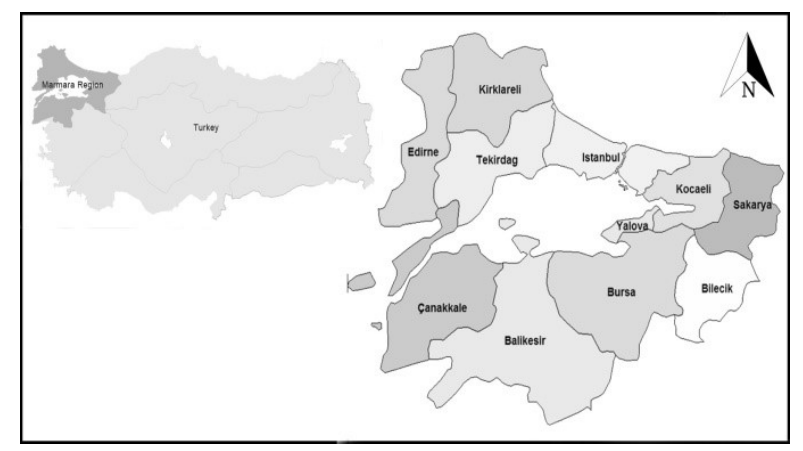

Table 1. The distribution of the samples regarding the province and animal species

\begin{tabular}{|c|c|c|c|c|c|c|c|}
\hline Provinces & $\begin{array}{l}\text { Number of } \\
\text { municipalities }\end{array}$ & $\begin{array}{l}\text { Number of } \\
\text { villages/ } \\
\text { districts }\end{array}$ & $\begin{array}{l}\text { Number } \\
\text { of sheep } \\
\text { herds }\end{array}$ & $\begin{array}{l}\text { Number } \\
\text { of sheep } \\
\text { samples }\end{array}$ & $\begin{array}{l}\text { Number } \\
\text { of goat } \\
\text { herds }\end{array}$ & $\begin{array}{l}\text { Number of } \\
\text { goat } \\
\text { samples }\end{array}$ & $\begin{array}{l}\text { Total number of } \\
\text { samples (sheep } \\
\text { and goats) }\end{array}$ \\
\hline Balikesir & 9 & 12 & 11 & 76 & 1 & 2 & 78 \\
\hline Bilecik & 6 & 12 & 7 & 60 & 5 & 25 & 85 \\
\hline Bursa & 5 & 7 & 3 & 46 & 4 & 26 & 72 \\
\hline Canakkale & 5 & 7 & 5 & 39 & 5 & 31 & 70 \\
\hline Edirne & 8 & 10 & 11 & 67 & 1 & 3 & 70 \\
\hline Istanbul & 6 & 11 & 7 & 50 & 4 & 35 & 85 \\
\hline Kirklareli & 6 & 14 & 12 & 48 & 3 & 21 & 69 \\
\hline Kocaeli & 4 & 10 & 10 & 60 & 2 & 10 & 70 \\
\hline Sakarya & 6 & 11 & 8 & 39 & 4 & 39 & 78 \\
\hline Tekirdag & 5 & 9 & 9 & 60 & 1 & 10 & 70 \\
\hline Yalova & 3 & 7 & 12 & 82 & 1 & 3 & 85 \\
\hline
\end{tabular}


All the sheep and goats were female and between 1.5 and 7 years old. In total, 627 and 205 blood samples were obtained from sheep and goat herds, respectively. No clinical manifestation of disease was observed in any of the animals. A small number of animals (16 sheep and 7 goats) had an abortion history. The sample size in this study was calculated in accordance with EpiTools epidemiological calculators (http://epitools.ausvet.com. $\mathrm{au} /$ content.php?page=home.In the calculation, the values used were as follows: assumed prevalence $50 \%$, desired precision 5\%, and confidence level 99\%. The distribution of the samples is shown in Table 1.

The sera were kept at $-20^{\circ} \mathrm{C}$ until testing. A Q fever antibody ELISA test kit including positive and negative control sera (IDEXX Laboratories, USA) was used to detect the presence of specific C. burnetii antibodies. The method was performed according to the manufacturer's instructions as already described (13, 14, 20). Dilutions of sera at 1:400 were prepared as recommended. Peroxidase-marked anti-ruminant immunoglobulin conjugate was used in order to measure specific antibodies $(14,20)$. The optical densities (OD) of the test sample and negative and positive controls were measured at $450 \mathrm{~nm}$ with an ELISA reader $(14,21)$. Results were shown as percentages of the OD reading of the test sample $(O D \%)(13,14,20)$. The results were interpreted according to the manufacturer's recommendation, in that $\mathrm{S} / \mathrm{P}$ values $\leq 30 \%$ were negative, values of $30-40 \%$ were suspect, and values $\geq 40 \%$ were positive. Pearson chi-squared analysis was used to find whether Q fever seropositivity statistically depended on animal age. Provincial seropositivity was also analysed with the same method.

\section{Results}

Seropositivity in sheep and goats was found to be $14.19 \%(\mathrm{n}=89)$ and $10.24 \%(\mathrm{n}=21)$, respectively. Total seroprevalence was observed as $13.22 \%(n=110)$. At least one seropositive result was obtained in 54 herds (44 of sheep and 10 of goats) out of the 126 (95 of sheep and 31 of goats), and as a percentage, seropositivity was 42.86 by herd. The seropositivity for sheep herds was $46.32 \%$ and for goat herds was $32.25 \%$.

In sheep with an abortion history seropositivity was $21.7 \%(\mathrm{n}=5)$. However, no goat with an abortion history was found to be seropositive. The total seroprevalence varied between $1.38 \%$ and $21.79 \%$ among provinces. On the other hand, the trend for percentages of seropositive herds in provinces was considerably higher and varied between $14.28 \%$ and $66.66 \%$.

The highest total seroprevalence and herd seropositivity for sheep among all the provinces was observed in Balikesir. The highest seroprevalence for goats was observed in Yalova, whereas the highest herd seropositivity for goats was found in Yalova and Sakarya. The seropositivity results are shown in Table 2.

Table 2. The provincial seroprevalence and the proportion of seropositive samples and herds including total values, sheep, and goats

\begin{tabular}{lllllll}
\hline Provinces & $\begin{array}{l}\text { Total } \\
\text { seropositivity } \\
\text { (sheep + goat) } \\
(\%)\end{array}$ & $\begin{array}{l}\text { Seropositive } \\
\text { herds (sheep } \\
+ \text { goat) } \\
(\%)\end{array}$ & $\begin{array}{l}\text { Seropositivity } \\
\text { of sheep } \\
\text { samples }(\%)\end{array}$ & $\begin{array}{l}\text { Seropositive } \\
\text { sheep herds } \\
(\%)\end{array}$ & $\begin{array}{l}\text { Seropositivity } \\
\text { of goat samples } \\
(\%)\end{array}$ & $\begin{array}{l}\text { Seropositive } \\
\text { goat herds } \\
(\%)\end{array}$ \\
\hline Balikesir & 21.79 & 66.66 & 22.36 & 72.72 & 0.00 & 0.00 \\
\hline Bilecik & 8.23 & 50.00 & 8.33 & 57.15 & 8.00 & 40.00 \\
\hline Bursa & 1.38 & 14.28 & 0.00 & 0.00 & 3.84 & 25.00 \\
\hline Canakkale & 15.71 & 40.00 & 20.51 & 40.00 & 9.67 & 40.00 \\
\hline Edirne & 18.57 & 33.33 & 19.40 & 36.36 & 0.00 & 0.00 \\
\hline Istanbul & 9.41 & 27.27 & 8.00 & 28.57 & 11.42 & 25.00 \\
\hline Kirklareli & 11.59 & 40.00 & 16.66 & 50.00 & 0.00 & 0.00 \\
\hline Kocaeli & 21.42 & 58.33 & 25.00 & 70.00 & 0.00 & 00 \\
\hline Sakarya & 10.25 & 33.33 & 5.12 & 25.00 & 15.38 & 50.00 \\
\hline Tekirdag & 11.42 & 50.00 & 8.33 & 44.44 & 30.00 & 600 \\
\hline Yalova & 16.47 & 46.15 & 14.63 & 41.66 & 66.66 & 53.33 \\
\hline
\end{tabular}

Table 3. The age distribution of seropositive animals

\begin{tabular}{lllllll}
\hline $\begin{array}{l}\text { Age } \\
\text { (years) }\end{array}$ & $\begin{array}{l}\text { Number of } \\
\text { animals (sheep } \\
\text { and goats) }\end{array}$ & $\begin{array}{l}\text { Number of } \\
\text { seropositive } \\
\text { animals } \\
\text { (sheep and goats) }\end{array}$ & $\begin{array}{l}\text { Number of } \\
\text { animals } \\
\text { (sheep) }\end{array}$ & $\begin{array}{l}\text { Number of } \\
\text { seropositive } \\
\text { animals } \\
\text { (sheep) }\end{array}$ & $\begin{array}{l}\text { Number of } \\
\text { animals (goats) }\end{array}$ & $\begin{array}{l}\text { Number of } \\
\text { seropositive } \\
\text { animals } \\
\text { (goats) }\end{array}$ \\
\hline $1-2$ & 195 & 26 & 128 & 18 & 67 & 8 \\
\hline $2-3$ & 219 & 24 & 175 & 22 & 44 & 2 \\
\hline $3-4$ & 180 & 21 & 137 & 14 & 43 & 7 \\
\hline $4-5$ & 137 & 26 & 104 & 22 & 33 & 4 \\
\hline $5-6$ & 81 & 9 & 66 & 9 & 15 & - \\
\hline $6-7$ & 20 & 4 & 17 & 4 & 3 & - \\
\hline
\end{tabular}


The age distribution of the seropositive animals is listed in Table 3. Most age groups proved to have almost the same number of seropositive individuals, with the exception of the oldest third of the animals between 5 and 7 years old.

Table 4. The chi-squared results

\begin{tabular}{lcc}
\hline Pearson chi-squared test & $\mathrm{X}^{2}$ value & $\mathrm{P}$ value \\
\hline Age groups and total seropositivity & 6.673 & 0.246 \\
\hline Provinces and total seropositivity & 24.671 & 0.006 \\
\hline Provinces and herd seropositivity & 8.864 & 0.545 \\
\hline
\end{tabular}

As shown in Table 4, total Q fever seropositivity was not found to be statistically significant depending on age $(0.246>0.05)$. The same insignificance is also valid for the relationship between herd seropositivity and provinces. However, there is a statistical significance $(0.006<0.05)$ in relationships between provinces in terms of total seropositivity. This significance might be due to the values of Balikesir (which yielded a significantly high standardised residual of 2.1) and Bursa (where a significantly low standardised residual of -2.8 was returned).

\section{Discussion}

The number of human outbreaks has drawn attention to $\mathrm{Q}$ fever and the disease has been jeopardising human and animal health as a re-emerging zoonosis $(4,6,11,25)$. According to the annual Q fever epidemiological report for 2017, 1,023 human cases were reported in the EU/EEA, 932 (91\%) of which were confirmed. As in previous years, the highest numbers of confirmed cases were reported by Spain, France, and Germany (7). In a recent study carried out on the at-risk groups in the Turkish context, $25.6 \%$ of people were found to be seropositive (5). The percentages found were similar to those obtained in different studies conducted in different provinces in Turkey such as Hatay, Istanbul, and Ankara.

The extent of the threat presented by $C$. burnetii is greater than may be assumed from diagnosed case numbers. The incidence is obviously higher in herds which include asymptomatic carriers (25). It is not possible to elucidate the real frequency of the disease without clinical data and diagnosis totals in animals and humans (15). Although the seropositivity varied between provinces, the total seroprevalence (13.22\%) revealed in this study is clear evidence of the existence of the recent infections and the past exposures within the whole region. Therefore, the results should be elaborated due to the possibility of either acute or chronic infection and augmented by periodical screening to evaluate the prevalence of the disease.

Considering subclinical coxiellosis, seroepidemiological studies showing the presence of the infection are very important for the surveillance and control of the disease
(13). It should be acknowledged that an already infected animal can spread the agent while giving a seronegative result $(13,14,18)$.

In the last two decades, several seroepidemiological studies on Q fever were carried out in small ruminant herds in Turkey $(3,9,12,14,19)$. The seroprevalence in sheep and the percentage of seropositive herds were found to be $10.5 \%$ and $44.7 \%$, respectively, in the eastern part of Turkey. Even though our study focuses on a different region, the results are comparable with the previous studies' (3); the serosurvey results do not vary drastically by region. This similarity shows that there is parity in the distribution of the infection in different regions of Turkey.

It is stipulated that an individual animal may be considered free of $\mathrm{Q}$ fever if the herd is free and is not associated with any prior serological or clinical data for Q fever (25). Because of the high percentage (42.85\%) of seropositive herds in the whole region and the provinces it includes, the risk of acquiring the infection and shedding the agent still exists for the animals which are not tested in the herds.

The seropositivity was found to be higher in aborted ewes and goats in some other studies (12, 14, 20 ). Kalender (12) reported $38.59 \%$ seropositivity in aborted ewes and $11.01 \%$ in non-aborted ewes in Elazı $\breve{g}$ and its neighbouring cities. Another study by Kilic and Kalender (14) also revealed a high rate of seropositivity in the eastern and south-eastern part of Turkey, with percentages of $16 \%$ in aborted and $7.6 \%$ in non-aborted ewes. In our study, the seropositivity $(21.7 \%)$ of aborted animals $(n=23)$ was higher than the total seropositivity. The samples belonging to animals without an abortion history represented the greater proportion of the samples. Therefore, the total seroprevalence of our study is in line with the seropositivity rate of non-aborted animals in previous studies.

In this study, the number of seropositive animals between 1 and 2 years old is quite close to the number of positive results in other age groups. It could be posited that the pathogen is disseminated to new generations in the screened herds, as has already been stated by other researchers (13). Other studies reported the seroprevalence of the disease in sheep as $5.4 \%$ in eastern Turkey and in cattle as $12.4 \%$ in central Turkey $(4,9)$. When it comes to the west of Turkey and the Marmara region, the number of seroprevalence studies is rather limited. Two other studies focusing on the Ege region, particularly Aydin province, illustrated the seroprevalence as $3 \%$ $(\mathrm{n}=3)$ and $21 \%(\mathrm{n}=42)$ in sheep.

A study carried out in southern Marmara including three provinces (Balikesir, Canakkale, and Tekirdag) reported the seroprevalence as $20 \%(n=151)$. The percentage of seropositive herds was found to be $81 \%$ $(\mathrm{n}=34)(13)$. Disparately, in our study focusing on the whole Marmara region the total seroprevalence and the proportion of seropositive herds were lower. This might be due to a number of reasons such as climatic differences, geographic location, sampling size, year, 
species screened, and cut-off value $(9,15)$. In our study, among all the provinces of the Marmara region, the rates of seropositivity in herds and provincially reached their highest in Balikesir at $66.66 \%$ and $21.79 \%$, respectively. The provincial seroprevalence rate in the present study is in line with the previous research. The seropositive herd percentage was found to be around three times as high as the total seroprevalence. This proportion also nearly quadrupled that of another study (13).

To our knowledge, no report on the seroprevalence of $\mathrm{Q}$ fever in small ruminants in the whole Marmara region is available except for the studies which focused on the western part of Turkey. Therefore, the results revealed in this study might be beneficial for future research undertaking comparison and contrast of the seroprevalence in the Marmara region with seroprevalence elsewhere. Q fever, which is a zoonotic infection, must be acknowledged as an issue of indisputable global concern (4). The solution for national and regional issues must be reached through the cooperation of veterinary and public health authorities (13). The OIE has also stated that especially domestic ruminants should be taken into consideration while effecting preventive actions to control the disease. It is only possible to get satisfactory results by implementing different measures simultaneously (25). The data gathered from seroepidemiological research like the present study and previous ones may guide and augment the control strategies against $\mathrm{Q}$ fever.

As a conclusion, the results confirm that $\mathrm{Q}$ fever infection persists and circulates within the studied sheep and goat herds in the 11 provinces of the Marmara region. The total seroprevalence, distribution of the seroprevalence between provinces and the number of seropositive herds point up the risk of this zoonosis and should urge the establishment of control and measuring systems to reduce the risk.

Conflict of Interests Statement: The authors declare that there is no conflict of interests regarding the publication of this article.

Financial Disclosure Statement: This work was supported by the Pendik Veterinary Control Institute.

Animal Rights Statement: The research was approved by the Local Ethics Committee for Animal Experimentation of the Pendik Veterinary Control Institute, Istanbul, Turkey. (Ethics Committee decision number 09-2/2018).

\section{References}

1. Bouvery N.A., Souriau A., Lechopier P., Rodolakis A.: Experimental Coxiella burnetii infection in pregnant goats: excretion routes. Vet Res 2003, 34, 423-433.

2. Centers for Disease Control and Prevention (CDC): Biological and chemical terrorism: strategic plan for preparedness and response. Recommendations of the CDC Strategic Planning Workgroup. MMWR Recomm Rep 2000, 49, 1-14.

3. Cetinkaya B., Kalender H., Ertas B.H., Muz A., Arslan N., Ongor H., Gurcay M.: Seroprevalence of coxiellosis in cattle, sheep and people in the east of Turkey. Vet Rec 2000, 146, 131-136.

4. Ceylan E., Berktas M., Keles I., Agaoglu Z.: Seroprevalence of Q fever in cattle and sheep in the east of Turkey. Asian J Anim Vet Adv 2009, 4, 114-121.

5. Çetinkol Y., Enginyurt Ö., Çelebi B., Yıldırım A.A., Çankaya S., Aktepe O.C.: Investigation of zoonotic infections in risk groups in Ordu University Hospital, Turkey. Niger J Clin Pract 2017, 20, 6-11.

6. Emery M.P., Ostlund E.N., Ait Ichou M., Ballin J.D., McFarling D., McGonigle L.: Coxiella burnetii serology assays in goat abortion storm. J Vet Diagn Invest 2014, 26, 141-145.

7. European Centre for Disease Prevention and Control. Q fever. In: ECDC. Annual epidemiological report for 2017. Stockholm, 2019.

8. Fournier P.E., Marriet T.J., Raoult D.: Diagnosis of Q fever. J Clin Microbiol 1998, 36, 1823-1834.

9. Gazyagci S., Aktas M.S., Kilic S., Babur C., Çelebi B., Duru S.Y.: Seroprevalence of Q fever in dairy cattle in the Konya province, Turkey. Rev Med Vet 2011, 162, 387-390.

10. Hatchette T.F., Hudson R.C., Schlech W.F., Campbell N.A., Hatchette J.E., Ratnam S., Raoult D., Donovan C., Marrie T.J.: Goat-associated Q fever: a new disease in Newfoundland. Emerg Infect Dis 2001, 7, 413-419.

11. Horigan M.W., Bell M.M., Pollard T.R., Sayers A.R., Pritchard G.C.: Q fever diagnosis in domestic ruminants: comparison between complement fixation and commercial enzyme-linked immunosorbent assays. J Vet Diagn Invest 2011, 23, 924-931.

12. Kalender H.: The incidence of Coxiella burnetii infection in ewes in Elaziğ and neighbouring provinces. Turk J Vet Anim Sci 2001, 25, 51-55.

13. Kennerman E., Rousset E., Gölcü E., Dufour P.: Seroprevalence of Q fever (coxiellosis) in sheep from the southern Marmara region, Turkey. Comp Immunol Microbiol Infect Dis 2010, 33, 37-45.

14. Kilic A., Kalender H.: A study of the correlation between Coxiella burnetii seropositivity and abortions in sheep in Eastern and Southeastern Turkey. Indian J Anim Res 2016, 50, 401-405.

15. Kilic S., Pasa S., Babur C., Ozlem M.B.: Investigation of Coxiella burnetii antibodies in sheep in Aydin region, Turkey. Rev Med Vet 2005, 156, 336-340.

16. Maurin M., Raoult D.: Q fever. Clin Microbiol Rev 1999, 12, 518-553.

17. McCault T.F., Williams J.C.: Developmental cycle of Coxiella burnetii: structure and morphogenesis of vegetative and sporogenic differentiations. J Bacteriol 1981, 147, 1063-1076.

18. Niemczuk K., Szymańska-Czerwińska M., Śmietanka K., Bocian Ł.: Comparison of diagnostic potential of serological, molecular and cell culture methods for detection of $\mathrm{Q}$ fever in ruminants. Vet Microbiol 2014, 171, 147-152.

19. Parin U., Kaya O.: Detection of Coxiella burnetii prevalence in bovine, ovine, and caprine herds. Ankara Univ Vet Fak Derg 2015, 62, 177-181.

20. Rousset E., Durand B., Berri M., Dufour P., Prigent M., Russo P., Delcroix T., Touratier A., Rodolakis A., Aubert M.: Comparative diagnostic potential of three serological tests for abortive $Q$ fever in goat herds. Vet Microbiol 2007, 124, 286-297.

21. Stephen S., Sangeetha B., Antony P.X.: Seroprevalence of coxiellosis ( $Q$ fever) in sheep and goat in Puducherry and neighbouring Tamil Nadu. Indian J Med Res 2014, 140, 785-787.

22. United States Department of Agriculture (USDA): Evaluation of factors that would initiate or propagate epidemic coxiellosis in the U.S. domesticated goat population. USDA:APHIS: VS: Centers for Epidemiology and Animal Health. Fort Collins, 2012. 
23. Waag D., Chulay J., Marrie T., England M., Williams J. Validation of an enzyme immunoassay for serodiagnosis of acute Q fever. Eur J Clin Microbiol Infect Dis 1995, 14, 421-427.

24. World Organisation for Animal Health (OIE). Manual of diagnostic tests and vaccines (mammals, birds, and bees) Volume $1,6^{\text {th }}$ Edition. Chapter 2.1.12. Q fever. Paris, 2008.

25. World Organisation for Animal Health (OIE). Terrestrial Manual, Chapter 2.1.16. Q fever. Paris, 2018.
26. World Organisation for Animal Health (OIE). Terrestrial Manual, Chapter 3.1.16. Q fever. Paris, 2019.

27. World Organisation for Animal Health (OIE). World Animal Health Information System. Disease Distribution Map 2018. http://www.oie.int/wahis_2/public/wahid.php/Diseaseinformatio $\mathrm{n} /$ Diseasedistributionmap. 